\title{
Green Scenarios for Power Generation in Vietnam by 2030
}

\author{
Vu H. M. Nguyen \\ Faculty of Electrical and Electronics Engineering \\ Ho Chi Minh City University of Technology and Education \\ Ho Chi Minh City, Vietnam \\ vunhm.ncs@hcmute.edu.vn
}

\section{Cuong V. Vo}

Faculty of Electrical and Electronic Engineering

Ho Chi Minh City University of Technology and Education

Ho Chi Minh City, Vietnam

cuongvv@hcmute.edu.vn

\author{
Luan D. L. Nguyen \\ Department of Urban Engineering \\ Ho Chi Minh City University of Architecture \\ Ho Chi Minh City, Vietnam \\ luan.nguyenleduy@uah.edu.vn
}

Binh T. T. Phan

Faculty of Electrical and Electronics Engineering Ho Chi Minh City University of Technology

Ho Chi Minh City, Vietnam

thanhbinh055@yahoo.com

\begin{abstract}
Energy for future sustainable economic development is considered one crucial issue in Vietnam. This article aims to investigate green scenarios for power generation in Vietnam by 2030. Four scenarios named as business as usual (BAU), low green (LG), high green (HG) and crisis have been proposed for power generation in Vietnam with projection to 2030. Three key factors have been selected for these scenarios, namely: (1) future fuel prices, (2) reduction of load demand caused by the penetration of LED technology and rooftop photovoltaic (PV) systems, and (3) the introduction of power generation from renewable sources. The least costly structure of power generation system has been found. $\mathrm{CO}_{2}$ emission reduction of $\mathrm{HG}$ in comparison to the BAU scenario and its effect on generation cost reduction are computed. Results show that BAU is the worst scenario in terms of $\mathrm{CO}_{2}$ emissions because of the higher proportion of power generation from coal and fossil fuels. LG and HG scenarios show their positive impacts both on $\mathrm{CO}_{2}$ emissions and cost reduction. $\mathrm{HG}$ is defined as the greenest scenario by its maximum potential on $\mathrm{CO}_{2}$ emission reduction $\left(\sim 146.92 \mathrm{Mt} \mathrm{CO}_{2}\right)$ in 2030. Additionally, selling mitigated $\mathrm{CO}_{2}$ can make green scenarios more competitive to $\mathrm{BAU}$ and Crisis in terms of cost. Two ranges of generation cost (4.3-5.5 and 6.07.7US\$cent $/ \mathbf{k W h}$ ) have been calculated and released in correspondence with low and high fuel price scenarios in the future. Using LED lamps and increasing the installed capacity of rooftop PVs may help reduce electric load demand. Along with the high contribution of renewable sources will make the HG scenario become more attractive both in environmental and economic aspects when the Crisis scenario comes. Generation costs of all scenarios shall become cheap enough for promoting economic development in Vietnam by 2030.
\end{abstract}

Keywords-green; scenario; least cost; optimum power generation; Vietnam

\section{INTRODUCTION}

Energy for sustainable development is one of the most crucial issues globally. In long-term energy planning, there are many uncertainty factors. In order to address the issue, green energy scenarios of IEA, BP, and China have been built which are projected to 20-30 years ahead [1-3]. Electricity usualy takes a high part of about $25 \%$ to $45 \%$ of total energy consumption. Finding the optimum structure for a power system in a competitive market with many constraints of transmission lines, the rules of the market constitute a multiresearched topic [4-8].

Vietnam has been considered as one of the most dynamic emerging countries with approximately $7 \%$ of annual Gross Domestic Products (GDP) increase in the last 20 years. That development has led to up to $15 \%$ increase of the yearly nationwide electricity power demand [9]. It is currently a big issue of Vietnam, relevant to the lack of primary fuels supplies. Another obstacle for power generation in Vietnam to meet the mentioned rapid economic development is environmental pollution [10]. Summarizing, supplying electricity power to meet the development of the economy is one of the most urgent issues of Vietnam. Vietnam Electricity Corporation (EVN) is a state-owned enterprise which is responsible for the whole country. EVN is required to cooperate with other relevant energy institutes and departments to prepare and release multiscale development plans for the national power system, where the periodic master plan which projects the development plan for the next 15 to 20 years ahead is expected as the most important outcome. The most recent relevant release is decision No 428/QD-TTg on March $18^{\text {th }} 2016$ [9]. Three development scenarios for Vietnam power system by 2030 have been proposed, namely Base, High ratio of renewable energy, and High load demand scenarios. However, numerous dubiousness regarding historical input data, mathematical functions, and results of load demand forecasting have been identified from those three scenarios. That vagueness made forecasting results of [9]. not verifiable. The shifts in power consumption awareness and generation sources have created three new 
factors which have a strong and direct effect on the power system: (1) the rapid growth of LED lamp technology, (2) the withdrawing of nuclear power from the national electric power structure (since June 2016), and (3) the release of Decision No. 11/QD-Tags on April 14 ${ }^{\text {th }} 2017$ [11]. The above factors made the scenario in [9] become inappropriate. New scenarios with updated forecasting objectives by 2030 must be studied and introduced to fulfill [9].

The purpose of this paper is to propose two state-of-the-art concepts of green power generation scenarios for Vietnam power system by 2030 . New concepts are strongly based on: the uncertainty of future fuel price, the penetration of LED technology and the increasing installed capacity of rooftop PV systems, and the difference in proportion of renewable energy exploited in Vietnam power system. A least cost objective function and its constraints in correspondence with each scenario will be established. A software named LINDO (linear, interactive, and discrete optimizer) is employed to figure the optimum structure of Vietnam power generation system with projection to 2030. The scope of the study is the power generation system in Vietnam only. The system is not yet capable to be put into a whole power system with constraints of trasmission lines and rules of a competitive maket.

\section{METHOD}

The scenarios are proposed based on uncertainty factors which have strong effects on sources (input) and load demands (output) of the power system. An objective function in terms of least cost and its constraints is employed to figure the optimum structure of Vietnam power generation system.

\section{A. Power Generation Scenarios}

Three variable key factors have been selected for creating power generation scenarios: future fuel price, reduction of load demand caused by the penetration of LED technology and rooftop PV systems, and the introduction of power generation from renewable sources. Table I presents two scenarios of Vietnam's fuel price by 2030. Proposals for the price of two common fuels used for power generation in Vietnam (coal and gas) are computed. Indicators show that there are big differences between the low and high scenarios. Two models computed by the two prestigious institutes have approximately a difference of $100 \%[11,12]$.

TABLE I. FUEL SCENARIOS

\begin{tabular}{|c|c|c|c|c|}
\hline Fuel price & Scenario & $\mathbf{2 0 2 0}$ & $\mathbf{2 0 2 5}$ & $\mathbf{2 0 3 0}$ \\
\hline \multirow{2}{*}{ Coal (\$/ton) } & High [12] & 93.5 & 98.3 & 103.3 \\
\cline { 2 - 5 } & Low [11] & 41.8 & 44.4 & 48.2 \\
\hline \multirow{2}{*}{ Gas (\$/MBtu) } & High [12] & 9.2 & 10.9 & 11.6 \\
\cline { 2 - 5 } & Low [11] & 4.9 & 5.5 & 5.7 \\
\hline
\end{tabular}

Since the price of LED lamps has been dramatically reduced, they are considered as the best choice for replacing conventional lamps in existing and new constructions. The strong penetration of LED lamps will lead to significant reduction of power load demand. Assumptions of lighting load share and LED penetration by 2030 are presented in Table II. Decision No 11/QD-TTg [11] promoted the installation wave of residential rooftop PV systems in the south regions of Vietnam. Taking effect since June $1^{\text {st }} 2017$, it was the first cornerstone of Vietnam's regulatory framework to encourage the development of solar energy utilization, which has been considered as one of the most effective ways to reduce the load demand. Assumptions of the rooftop PV systems are shown in Table III. Electric load demand scenarios resulted by the penetration of LED lamp technology are shown in Table IV. The High values are forecasted, while the Low values are reduced by the penetration of LED technology from $1.2 \%$ to $6.2 \%$ and $1.5 \%$ to $8.2 \%$, respectively.

TABLE II. ASSUMPTIONS OF LIGHTING LOAD AND LED

\begin{tabular}{|c|c|c|c|}
\hline Year & $\mathbf{2 0 2 0}$ & $\mathbf{2 0 2 5}$ & $\mathbf{2 0 3 0}$ \\
\hline Lighting consumption (\%) [9] & 23 & 21 & 19 \\
\hline Capacity factor of lighting & \multicolumn{3}{|c|}{0.75} \\
\hline Total lighting $\mathbf{P}_{\max }(\%)[\mathbf{9}]$ & 30.7 & 28.0 & 25.3 \\
\hline Penetration of LED (\%) & 10 & 30 & 65 \\
\hline Energy reduction by LED (\%) & \multicolumn{3}{|c}{50} \\
\hline
\end{tabular}

TABLE III. ASSUMPTIONS OF ROOFTOP PV SYSTEMS

\begin{tabular}{|c|c|c|c|}
\hline \multirow{2}{*}{ Year } & $\begin{array}{c}\text { Residential } \\
\text { consumption [9] (\%) }\end{array}$ & \multicolumn{2}{|c|}{ Penetration of rooftop PVs (\%) } \\
\cline { 3 - 4 } & 34.75 & Low & High \\
\hline $\mathbf{2 0 2 0}$ & 31.36 & 2 & 2 \\
\hline $\mathbf{2 0 2 5}$ & 28.63 & 10 & 15 \\
\hline $\mathbf{2 0 3 0}$ & 20 & 30 \\
\hline
\end{tabular}

TABLE IV. ASSUMPTIONS OF LIGHTING LOAD AND LED

\begin{tabular}{|c|c|c|c|c|c|c|}
\hline \multirow{2}{*}{ Year } & \multicolumn{3}{|c|}{ Demand (TWh) } & \multicolumn{3}{c|}{ Pmax (GW) } \\
\cline { 2 - 7 } & High [13] & Low & Reduction (\%) & High [14] & Low & Reduction (\%) \\
\hline $\mathbf{2 0 2 0}$ & 230.20 & 227.55 & 1.2 & 40.33 & 39.71 & 1.5 \\
\hline $\mathbf{2 0 2 5}$ & 349.95 & 338.93 & 3.2 & 60.84 & 58.28 & 4.2 \\
\hline $\mathbf{2 0 3 0}$ & 511.27 & 479.70 & 6.2 & 87.56 & 80.35 & 8.2 \\
\hline
\end{tabular}

Considering the combination of the development of rooftop PV systems and the penetration of LEDs, an option of deeply low load demand is proposed. A concept of cumulative reduction is presented in Table $\mathrm{V}$. It is noted that the rooftop PVs will take to the reduction of TWh only while $\mathrm{P}_{\max }$ is not affected because $\mathrm{P}_{\max }$ normally occurs at evening (at around 7:00 pm).

TABLE V. CUMMULATIVE ELECTRIC LOAD DEMAND REDUCTION BY LED AND ROOFTOP PV SYSTEMS

\begin{tabular}{|c|c|c|c|c|}
\hline \multirow{2}{*}{ Year } & \multicolumn{4}{|c|}{ Demand } \\
\cline { 2 - 5 } & $\begin{array}{c}\text { Low } \\
\text { (TWh) }\end{array}$ & $\begin{array}{c}\text { Reduction } \\
(\mathbf{\%})\end{array}$ & $\begin{array}{c}\text { Deeply low } \\
\text { (TWh) }\end{array}$ & $\begin{array}{c}\text { Reduction } \\
(\%)\end{array}$ \\
\hline $\mathbf{2 0 2 0}$ & 225.97 & 1.8 & 225.97 & 1.8 \\
\hline $\mathbf{2 0 2 5}$ & 328.30 & 6.2 & 322.98 & 7.7 \\
\hline $\mathbf{2 0 3 0}$ & 452.23 & 11.5 & 438.50 & 14.2 \\
\hline
\end{tabular}

Table VI indicates the maximum GWh and MW of power generation from renewable sources by 2030 [9]. However, the Decision No. 2068/QD-TTg, issued on November $25^{\text {th }} 2015$ [15] stipulated another option in which the values of exploitable renewable sources are much higher than the ones presented in Table VI (see Table VII). It is noted that high values of biomass are assumed to be reach up to $70 \%$ of that in [15] only. When combining those above factors, various scenarios are generated. Four difference scenarios are proposed 
and shown in Table VIII: (1) Business as usual (BAU) is similar to what happened during the last 5 years in case of low fuel price, high load demand, and low sharing of renewable energy generation, (2) Low green (LG) represents the case of low fuel price, low load demand, and high sharing of renewable energy, (3) High green (HG) is generated to perform the conditions of high fuel price, deeply low load demand, and high renewable energy, and (4) Crisis scenario is the case of high fuel price, low load demand and low renewable energy.

TABLE VI. SCENARIOS OF LOW RENEWABLE ENERGY [9]

\begin{tabular}{|c|c|c|c|c|}
\hline Generation & Unit & $\mathbf{2 0 2 0}$ & $\mathbf{2 0 2 5}$ & $\mathbf{2 0 3 0}$ \\
\hline \multirow{2}{*}{ Mini hydro } & TWh & 11.1 & 12.4 & 17.7 \\
\cline { 2 - 5 } & GW & 3.8 & 5.2 & 6.8 \\
\hline \multirow{2}{*}{ Biomass low } & TWh & 2.7 & 4.8 & 12.6 \\
\cline { 2 - 5 } & GW & 0.5 & 0.9 & 2.4 \\
\hline \multirow{2}{*}{ Wind low } & TWh & 2.1 & 4.0 & 12.0 \\
\cline { 2 - 5 } & GW & 0.8 & 2.0 & 6.0 \\
\hline \multirow{2}{*}{ Solar low } & TWh & 8.8 & 12.8 & 18.9 \\
\cline { 2 - 5 } & GW & 6.1 & 8.0 & 12.0 \\
\hline
\end{tabular}

TABLE VII. SCENARIOS OF HIGH RENEWABLE ENERGY [15]

\begin{tabular}{|c|c|c|c|c|}
\hline Generation & Unit & $\mathbf{2 0 2 0}$ & $\mathbf{2 0 2 5}$ & $\mathbf{2 0 3 0}$ \\
\hline \multirow{2}{*}{$\begin{array}{c}\text { Biomass high } \\
\text { (70\% of }[8])\end{array}$} & TWh & 8.0 & 19.2 & 36.0 \\
\cline { 2 - 5 } & GW & 1.5 & 3.6 & 6.9 \\
\hline \multirow{2}{*}{ Wind high } & TWh & 2.7 & 6.0 & 15.4 \\
\cline { 2 - 5 } & GW & 1.0 & 3.0 & 7.7 \\
\hline \multirow{2}{*}{ Solar high } & TWh & 8.8 & 23.8 & 34.3 \\
\cline { 2 - 5 } & GW & 6.1 & 15.0 & 21.8 \\
\hline
\end{tabular}

TABLE VIII. PROPOSED SCENARIOS

\begin{tabular}{|c|c|c|c|}
\hline Scenario & Fuel price & Load demand & Renewable energy \\
\hline BAU & Low & High & Low \\
\hline LG & Low & Low & High \\
\hline HG & High & Deeply low & High \\
\hline Crisis & High & Low & Low \\
\hline
\end{tabular}

Vietnam's economy has been performing well during the last 30 years. This boosts the electric load demand and therefore sustainable development solutions for energy supply must be considered. However, Vietnam's elasticity of electricity demand has still remained at a high value of more than 1.7 [9] due to the ineffective implementation of energy efficiency policies and frameworks, while the exploitation of renewable energy has been neglected. Hence, energy scenarios have to be built comprehensively with aim to promote the exploitation of renewable energy and to reduce the electric load demand. These are the essential conditions to reform a green economy for Vietnam. When the price of fuel increases, then the load demand must be reduced and renewable energy must be considered more seriously. This is a great opportunity for developing renewable energy in Vietnam.

\section{B. Objective Function}

The objective function of the optimal structure for generation is the function where the power generation cost is minimized in 2020, 2025, and 2030.

$$
O=\sum_{g, q, t, y} W_{y} . C E_{g, y} \cdot X_{g, q, t, y} \rightarrow \min
$$

where $g$ represents the type of generation (hydro, coal, gas, mini-hydro, biomass, wind, photovoltaic, import), $q$ is the load pattern identified by number 1 to 8 (see Table IX), $t$ is the time of a day (from 1:00 to 24:00), $y$ is the considered year (2020, $2025,2030), C E_{g, y}$ is the generation cost of power plant $g$ at year $y, X_{g, q, t, y}$ is the least-cost generation power of power plant $g$, corresponding to the load pattern $q$ at time $t$ of the year $y$, and $W_{y}$ is the net present value coefficient, calculated by (2):

$$
W_{y}=\left[\frac{1+r}{1+\varepsilon}\right]^{y-2014}
$$

where $r$ is the interest rate, estimated at $8 \%$ per year, and $\varepsilon$ is the inflation rate, estimated at $4 \%$ per year.

The generation cost $C E_{g, y}$ [US\$/kWh] of the power plant $g$ at year $y$ is calculated by:

$$
C E_{g, y}=\frac{\sum\left(F_{g, y}+A_{g, y}+M O_{g, y}\right)}{Q_{g, y}}
$$

where $F_{g, y}$ is the fuel price, $A_{g, y}$ is the yearly investment depreciation, $M O_{g, y}$, is the operation and maintenance cost, and $Q_{g, y}$ is the power production of power plant $g$ at year $y[\mathrm{kWh}]$.

The annual investment depreciation $A_{g, y}$ [US\$/year] is calculated by:

$$
A_{g, y}=\frac{r_{0} \cdot\left(1+r_{0}\right)^{n}}{\left(1+r_{0}\right)^{n}-1} \times I_{g, y} \times C_{g, y} \times 10^{3}
$$

where $r_{0}$ is the ODA interest rate, estimated at $3.8 \% /$ year, $n$ is the lifetime of the power plant $g$, [year], $I_{g, y}$ is the investment cost per unit of a power plant $g$ at year $y$, [US $\$ / \mathrm{kW}$, and $C_{g, y}$ is the installed capacity of the power plant $g$ at year $y,[\mathrm{MW}]$.

\section{Constraints}

The constraints of the suggested objective function are: load demand, upper limit of generation power, reserve power capacity, variable limitation of generation power between two consecutive hours, and capacity factor.

\section{1) Load Demand}

In order to meet load demand, it is required for the total generation power to be equal with the load power demand:

$$
\sum_{g} X_{g, q, t, y}=P_{q, t, y}
$$

where $P_{q, t, y}$ is the load power demand for pattern $q$ at the time $t$ of year $y$.

\section{2) Maximum Generation Power}

The generation power of power plant $g$, corresponding to the load pattern $q$ at time $t$ of the year $y$ must be lower than the maximum generation power of that power plant:

$$
X_{g, q, t, y} \leq X_{g, q, t_{\max . q}, y}
$$

where $t_{\max , q}$ is the time that the power plant $g$ operates at maximum power, corresponding to the load pattern $q$. 
The generation power at the time $t_{\max , q}$ for the load pattern $q$ must be lower than the total installed capacity of the power plant $g$ in the year $y$ :

$$
X_{g, q, t_{\max . q}, y} \leq C_{g, y}
$$

The power production of a power plant $g$ in the year $y$ must be lower than the upper capacity limit of that power plant:

$$
Q_{g, y} \leq Q_{\max . g, y}
$$

where $Q_{\max , g, y}$ is the maximum generation power of the power plant $g$ in the year $y$.

\section{3) Maximum Installed Capacity}

The maximum installed capacity of power generations is decided by the upper limitation of input primary energies which can be exploited, and the funding sources which can be used for constructing new power facilities in certain years. The installed capacity of a power plant $g$ in the year $y$ must be lower than the maximum installed capacity of that plant at the same time:

$$
C_{g, y} \leq C_{\max . g, y}
$$

\section{4) Reserve Power Capacity}

To assure the reliability of the power system, the total installed capacity of generation facilities in the year $y$ must be higher than the maximum demand power including reserve power:

$$
\sum C_{g, y} \leq\left(1+\alpha_{y}\right) \cdot P_{\max . y}
$$

where $P_{\max , y}$ is the maximum power demand in year $y, \alpha_{\mathrm{y}}$ is the reserve limitation in the year $y$.

Reserve power capacity is closely related to the loss of load expectation (LOLE) which is chosen as an indicator of power system reliability in this study. Values of $\alpha_{y}$ do not include the installed capacity of renewable energy sources, i.e. biomass, wind, and solar generation.

\section{5) Capacity Factor}

In each pattern of power load, the diurnal power generation of a power plant $g$ must be less than its capacity factor multiplied by the theoretical power generation production:

$$
\sum_{t} X_{g, q, t, y} \leq 24 \cdot L_{g, q} \cdot C_{g, y}
$$

where $L_{g, q}$ is the capacity factor of the power plant $g$ corresponding to load pattern $q$.

\section{6) Limitation of Generation Power Between Two Consecutive Hours}

The relation between the probability of changing load power demand and the generation capacity of power plant $g$ is presented as:

$$
\left(1-\rho_{g}\right) \cdot X_{g, q, t, y} \leq X_{g, q, t, y} \leq\left(1+\rho_{g}\right) \cdot X_{g, q, t-1, y}
$$

where $\rho_{g}$ is defined as the limitation of generation power variation between two consecutive hours of power plant $g$.

\section{INPUT DATA COLLECTION}

\section{A. Load Pattern}

Instead of using historical hourly data of power load, 8 load patterns, representing 8 typical groups of load profile in a year, are employed to minimize calculation time (Table IX [16]).

TABLE IX. LOAD PATTERNS OF VIETNAM POWER SYSTEM [16]

\begin{tabular}{|c|c|}
\hline No. & Pattern \\
\hline 1 & Tet holidays \\
\hline 2 & W: 1,2 \\
\hline 3 & W: $3,4,5$ \\
\hline 4 & W: $6,7,8$ \\
\hline 5 & W: $9,10,11,12$ \\
\hline 6 & S \& N: 1,2 \\
\hline 7 & S \& N: $3,4,5,6,7,8,9$ \\
\hline 8 & S \& N: $10,11,12$ \\
\hline \multicolumn{2}{|c|}{ W: working day, S: Sunday, N: National holiday }
\end{tabular}

\section{B. Maximum Installed Capacity}

Maximum installed capacities of hydro, mini-hydro, coal, and gas generations are officially cited from [8] and [15] (Table $\mathrm{X}$ ). The maximum installed capacities of biomass, wind and $\mathrm{PV}$ are presented in Tables VI and VII.

TABLE X. MAXIMUM INSTALLED CAPACITY $(\mathrm{GW})[8,15]$

\begin{tabular}{|c|c|c|c|}
\hline Power generation & $\mathbf{2 0 2 0}$ & $\mathbf{2 0 2 5}$ & $\mathbf{2 0 3 0}$ \\
\hline Hydro & 18.16 & 18.63 & 21.22 \\
\hline Coal & 26.71 & 47.47 & 65.89 \\
\hline Gas & 9.47 & 17.55 & 23.23 \\
\hline Mini-hydro & 3.80 & 5.20 & 6.80 \\
\hline
\end{tabular}

\begin{tabular}{|c|c|c|c|c|c|c|}
\hline \multirow[t]{2}{*}{ Year } & \multirow{2}{*}{$\begin{array}{c}\text { LOLE } \\
\text { target } \\
(\mathrm{h} / \mathrm{y})\end{array}$} & \multirow{2}{*}{$\begin{array}{c}\text { Reserve } \\
\text { margin } \\
(\%)\end{array}$} & \multicolumn{2}{|c|}{$\begin{array}{l}\text { Demand } P_{\max } \\
(G W)\end{array}$} & \multicolumn{2}{|c|}{$\begin{array}{c}\text { Installed capacity } \\
(\text { GW) }\end{array}$} \\
\hline & & & High & Low & High & Low \\
\hline 2020 & 24 & 25 & 40.33 & 39.71 & 50.41 & 49.64 \\
\hline 2025 & 24 & 20 & 60.84 & 58.28 & 73.01 & 69.94 \\
\hline 2030 & 24 & 20 & 87.56 & 80.35 & 105.07 & 96.42 \\
\hline
\end{tabular}

\section{Reserved Capacity}

Table XI presents the reserve margin and installed capacity of Vietnam power system by 2030. It is worth noting that the reserved capacity does not include renewable energy sources.

TABLE XI. RESERVE MARGIN AND INSTALLED CAPACITY [9]

\section{Capacity Factor}

The fact that some power resources depend on climate and other natural conditions leads to dependence characteristics of capacity factor on natural conditions. For example, the capacity factor of a solar power plant depends on the variation of solar radiation, the capacity factor of a wind farm may be affected by the changes of wind speed, and the capacity factor of a hydro power plant will vary when the water flow alters. Therefore, it is required to verify the exact capacity factor of each type of energy source before taking them into account. 


\section{1) Solar Power Plant}

In order to identify the capacity factor of a solar power plant, three important constraints must be accounted for:

- Sunny time: useful solar radiation could only be collected from 6:00 to 18:00. The other times, there may be some frail radiation in some regions but it cannot be used.

- Radiation intensity: solar radiation intensity varies continuously throughout the day.

- Geographical location: Regions which have stable radiation duration are the Central, Highland and Southern of Vietnam [17].

Therefore, it is recommended that solar power plants should be constructed around those regions. Based on the solar radiation values of Central and Southern provinces presented in [17], the capacity factor of a solar power plant could be calculated. Solar radiation of Central coast area, and capacity factors of PV power plants are presented in Table XII.

\section{2) Wind Power Plant}

At the height of $60 \mathrm{~m}$ above sea level, wind energy could only be obtained effectively in $\mathrm{Ca} \mathrm{Mau}$, a mountainous province of Highland, and some provinces of Central coast area [18]. The biggest wind farm of the South East Asia, Tuy Phong wind farm, is located in Binh Thuan province. However, because of the unstable wind speed, the generation power of Tuy Phong has high variations. Based on forecasted wind speed [18], the capacity factor of a wind power plant located in Vietnam could be computed. Table XII presents the capacity factors corresponding to the monthly variation of wind speed in Central coastal Vietnam.

\section{3) Hydro and Mini-Hydro Power Plants}

As mentioned above, generation capacity of hydro and mini hydro plants strongly depends on water sources and rainfall. Based on historical data involving climate conditions, annual average rainfall, and rainfall predictions, along with the assumption that there will be no unusual changes in the local natural conditions, the capacity factor of a hydro power plant could be calculated. Regarding a mini hydro power plant, the current national regulations on dam design stipulate a very small limitation for height, leading to the result that generation power of a mini hydro power plant is closely connected to local rainfall. Capacity factors of hydro and mini hydro power plants are presented in Table XIII.

\section{4) Capacity Factors of Other Power Plants}

In theory, coal, gas, and biomass power plants can operate throughout the year. However, they need to be maintained periodically. It normally takes them at least 30 to 45 days per year to stop operating for maintenance or for accidental shutdown. Therefore, in this research, the capacity factors of coal, gas, and biomass generations are proposed to be 0.8 , as shown in Table XIII.

\section{E. Limitation of Generation Power Variation Between Two Consecutive Hours of a Power Plant}

For solar and wind power plants, the generation ability between two consecutive hours totally depends on local natural conditions, i.e. wind speed changes or variations of solar radiation at different times of a day.

TABLE XII. SOLAR RADIATION, WIND SPEED IN CENTRAL COAST AREA AND PV, WIND GENERATION CAPACITY FACTORS $[17,18]^{]}$

\begin{tabular}{|c|c|c|c|c|}
\hline \multirow[b]{2}{*}{ Month } & \multicolumn{2}{|c|}{ Solar } & \multicolumn{2}{|c|}{ Wind } \\
\hline & $\begin{array}{c}\text { Solar } \\
\text { radiation } \\
\left(\mathbf{k W h} / \mathbf{m}^{2} . \text { day }\right)\end{array}$ & $\begin{array}{c}\text { Capacity } \\
\text { factor } \\
\text { [per unit] }\end{array}$ & $\begin{array}{l}\text { Wind } \\
\text { speed } \\
(\mathrm{m} / \mathrm{s})\end{array}$ & $\begin{array}{c}\text { Capacity } \\
\text { factor } \\
\text { (per unit) }\end{array}$ \\
\hline 1 & 3.6 & 0.32 & 8.0 & 0.75 \\
\hline 2 & 4.8 & 0.43 & 7.0 & 0.56 \\
\hline 3 & 5.2 & 0.47 & 5.8 & 0.34 \\
\hline 4 & 5.6 & 0.50 & 4.2 & 0.10 \\
\hline 5 & 5.2 & 0.47 & 5.0 & 0.19 \\
\hline 6 & 5.2 & 0.47 & 5.7 & 0.32 \\
\hline 7 & 5.2 & 0.47 & 6.5 & 0.41 \\
\hline 8 & 5.2 & 0.47 & 6.5 & 0.41 \\
\hline 9 & 4.4 & 0.40 & 5.5 & 0.29 \\
\hline 10 & 4.4 & 0.40 & 4.3 & 0.10 \\
\hline 11 & 4.0 & 0.36 & 6.7 & 0.44 \\
\hline 12 & 3.6 & 0.32 & 8.0 & 0.75 \\
\hline
\end{tabular}

TABLE XIII. GENERATION CAPACITY FACTORS

\begin{tabular}{|c|c|c|c|c|c|c|}
\hline Month & $\begin{array}{c}\text { No. of load } \\
\text { pattern }\end{array}$ & Hydro & $\begin{array}{c}\text { Mini- } \\
\text { hydro }\end{array}$ & Wind & PV & $\begin{array}{c}\text { Coal, gas, } \\
\text { biomass }\end{array}$ \\
\hline 1 & $1,2,6$ & 0.51 & 0.20 & 0.75 & 0.32 & 0.8 \\
\hline 2 & $1,2,6$ & 0.48 & 0.20 & 0.56 & 0.43 & 0.8 \\
\hline 3 & 3,7 & 0.48 & 0.25 & 0.34 & 0.47 & 0.8 \\
\hline 4 & 3,7 & 0.82 & 0.72 & 0.10 & 0.50 & 0.8 \\
\hline 5 & 3,7 & 0.92 & 0.60 & 0.19 & 0.47 & 0.8 \\
\hline 6 & 4,7 & 0.76 & 0.78 & 0.32 & 0.47 & 0.8 \\
\hline 7 & 4,7 & 0.76 & 0.90 & 0.41 & 0.47 & 0.8 \\
\hline 8 & 4,7 & 0.92 & 1.00 & 0.41 & 0.47 & 0.8 \\
\hline 9 & $5,7,8$ & 0.82 & 0.75 & 0.29 & 0.40 & 0.8 \\
\hline 10 & $5,7,8$ & 0.58 & 0.60 & 0.10 & 0.40 & 0.8 \\
\hline 11 & $5,7,8$ & 0.58 & 0.27 & 0.44 & 0.36 & 0.8 \\
\hline 12 & $5,7,8$ & 0.58 & 0.21 & 0.75 & 0.32 & 0.8 \\
\hline
\end{tabular}

\section{1) Wind Power Plant}

The generation capability between two consecutive hours depends on the changes of wind speed at the location where the wind-mill is constructed. However, the difference on wind speed between two consecutive hours is very small, at $1-2 \mathrm{~m} / \mathrm{s}$ (approximately 15\%).

\section{2) Solar Power Plant}

As mentioned, two reasons which lead to the change of generation power between two consecutive hours of a solar power plant are the variation of solar radiation intensity during the day and the duration of sunny time per day. However, changes of solar radiation between two consecutive hours are still petite and accounted for around $15 \%$ as in the wind power case. Table XIV presents the limitation of generation power variation between two consecutive hours of different types of power plants which may be called as the load traceability of power generation.

TABLE XIV. LOAD TRACEABILITY RATIO OF POWER GENERATION (\%)

\begin{tabular}{|c|c|c|c|c|c|}
\hline Hydro & Coal & Gas & Biomass & Wind & PV \\
\hline 10 & 20 & 60 & 20 & 15 & 15 \\
\hline
\end{tabular}




\section{F. $\mathrm{CO}_{2}$ Emissions and Prices}

\section{1) $\mathrm{CO}_{2}$ Emission Factor}

The emission factors of $\mathrm{CO}_{2}$ for different energy sources in Vietnam are shown in Table XV. Emission factors of wind energy and solar energy are cited from [20,21].

TABLE XV. $\quad \mathrm{CO}_{2}$ EMISSION FACTORS IN VIETNAM

\begin{tabular}{|c|c|c|c|c|c|c|}
\hline Unit & Coal & Gas & Biomass & Hydro & PV & Wind \\
\hline$\left[\mathrm{g}-\mathrm{CO}_{2} / \mathrm{kWh}\right]$ & 1,473 & 464 & 20 & 11 & 40 & 11.7 \\
\hline
\end{tabular}

\section{2) $\mathrm{CO}_{2}$ Prices}

Although the Clean Development Mechanism (CDM) issued by Kyoto Protocol (1997) has not been extended since 2012, international $\mathrm{CO}_{2}$ trading market is still operating. Selling prices of $\mathrm{CO}_{2}$ in the global market are chosen at 18,20, and $25 \mathrm{US} \$ /$ short $\mathrm{t}-\mathrm{CO}_{2}$, for year 2020, 2025, and 2030, respectively. Those are the lowest prices according to [22].

\section{G. Levelized Cost}

In Vietnam, renewable power plants will be offered a fixed selling tariff (Table XVI). Reference values relevant to investment, power factor, lifetime, fuel consumption per unit production, operation and maintenance cost, fuel price are included in Table XVII. They are categorized as levelized cost. The values are cited from [9].

TABLE XVI. ELECTRICITY PRICES BUYED BY EVN

\begin{tabular}{|c|c|c|c|c|}
\hline Unit & Biomass [23] & Wind [24] & PV [11] & Import [9] \\
\hline [US\$cent/kWh] & 7.4 & 7.8 & 9.35 & 6.02 \\
\hline
\end{tabular}

TABLE XVII. LEVELIZED COST OF CONVENTIONAL POWER PLANTS [9]

\begin{tabular}{|c|c|c|c|c|c|c|c|c|c|c|}
\hline \multirow{2}{*}{ Indicator } & \multirow{2}{*}{ Unit } & \multicolumn{3}{|c|}{ Gas } & \multicolumn{3}{|c|}{ Coal } & \multicolumn{3}{|c|}{ Hydro } \\
\hline & & 2020 & 2025 & 2030 & 2020 & 2025 & 2030 & 2020 & 2025 & 2030 \\
\hline Investment & $\mathrm{US} \$ / \mathrm{kW}$ & 1,224 & 1,660 & 1,660 & 1,400 & 1,850 & 1,850 & 1,500 & 1,500 & 1,500 \\
\hline Energy consumption & $\mathrm{kcal} / \mathrm{kWhe}$ & 2,457 & 1,870 & 1,870 & 2,098 & 1,720 & 1,720 & & & \\
\hline Lifetime & $\mathrm{yr}$ & \multicolumn{3}{|c|}{25} & \multicolumn{3}{|c|}{30} & \multicolumn{3}{|c|}{50} \\
\hline Fixed O\&M & US\$/kW.yr & 24.5 & 28 & 28 & 42 & 43.5 & 43.5 & 5 & 5 & 5 \\
\hline Variable O\&M & US\$/MWhe & 0.88 & 1.37 & 1.37 & 0.15 & 3 & 3 & 2 & 2 & 2 \\
\hline Interest rate (WB-IDA SUF) & $\%$ & \multicolumn{9}{|c|}{3.8} \\
\hline Fuel price - low & US\$/MBtu & 4.88 & 5.46 & 5.69 & 1.6 & 1.7 & 1.9 & & & \\
\hline Fuel price - high & US\$/MBtu & 9.16 & 10.9 & 11.6 & 3.6 & 3.8 & 4.0 & & & \\
\hline Heat value (LHV) & $1000 \mathrm{kcal} / \mathrm{kg}$ & 9.8 & 8.5 & 8.5 & 6.5 & 6.5 & 6.5 & & & \\
\hline
\end{tabular}

\section{RESULTS}

When the input parameters are inserted into LINDO software, optimal generation scenarios of installed capacity and power generation production based on different power sources for the years 2020, 2025, and 2030 are generated as final results. The following values are calculated: $\mathrm{CO}_{2}$ emission capacity, electricity selling prices in case of non-purchasing mitigated- $\mathrm{CO}_{2}$, and electricity selling prices with sharing by mitigated- $\mathrm{CO}_{2}$ trading.

\section{A. Installed Capacity}

Optimum installed capacity of power generation is presented in Figure 1.

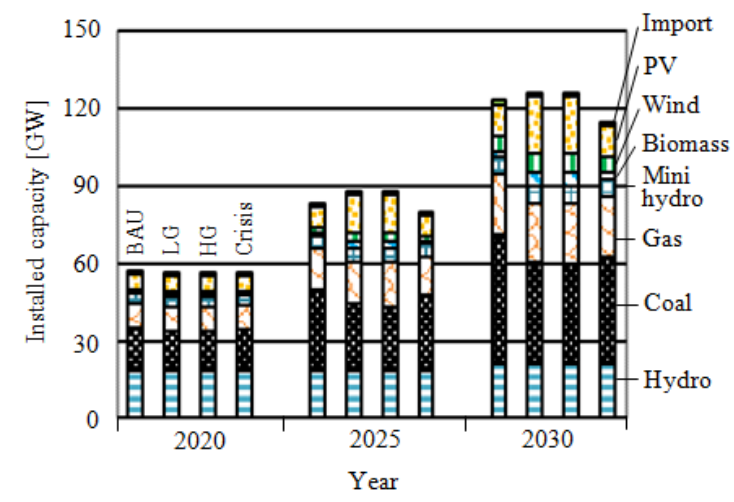

Fig. 1. Optimum installed capacity
Hydro installed capacity is around $18.1 \mathrm{GW}, 18.6 \mathrm{GW}$, and $21.2 \mathrm{GW}$ in 2020,2025 , and 2030 respectively reducing from $32 \%$ to $16.8 \%$. It reaches its upper limit of installation and does not change through the scenarios. Coal generation capacity on the other hand, is dramatically increased from around 15.8$17 \mathrm{GW}$ in 2020 to $24.6-29.3 \mathrm{GW}$ in 2025 , and $38.9-49.9 \mathrm{GW}$ in 2030 changing its percentage of total capacity from about $27.8 \%$ to $40.6 \%$. Gas generation capacity is increased by years but not changed much through different scenarios at around $9.5 \mathrm{GW}$ in $2020,15.6 \mathrm{GW}$ in 2025 , and $23.2 \mathrm{GW}$ in 2030 . In percentage of total, it varies in the range of $16.6 \%$ to $20.3 \%$. The other generations are all reaching their upper limit installation. All scenarios have reserved capacity at more than $20 \%$ not including renewable sources.

\section{B. Power Generation Production}

Figure 2 illustrates the computed-results of optimum electricity generations. Hydro generation reaches its upper limit from 66.3 to $68.6 \mathrm{TWh}$ from 2020 to 2030 respectively decreasing its percentage from $35.8 \%$ to $13.9 \%$. Coal generation increases dramatically to meet the increasing load demand. The generation takes a very high percentage from $41.5 \%$ to $65.8 \%$. Gas generation shares $19 \%$ to $26.3 \%$ of total, depending on the years and scenarios. Other generations are all reaching their upper limits.

\section{C. $\mathrm{CO}_{2}$ Emission Capacity}

$\mathrm{CO}_{2}$ emissions of the power generation system are shown in Figure 3. BAU scenario has the highest emissions of $188.9 \mathrm{Mt}-$ $\mathrm{CO}_{2}, 341.8 \mathrm{Mt}-\mathrm{CO}_{2}$, and $516.9 \mathrm{Mt}-\mathrm{CO}_{2}$ in 2020, 2025, and 2030 
respectively. Lowest emissions are resulted by the HG scenario and are reduced by $5.9 \%$ (2020), 20.4\% (2025), and $28.4 \%$ (2030) compared to BAU. This is caused by a considerable increase of renewable sources, and very low load demand. Details of reduction in capacity of emissions are presented in Table XVIII.

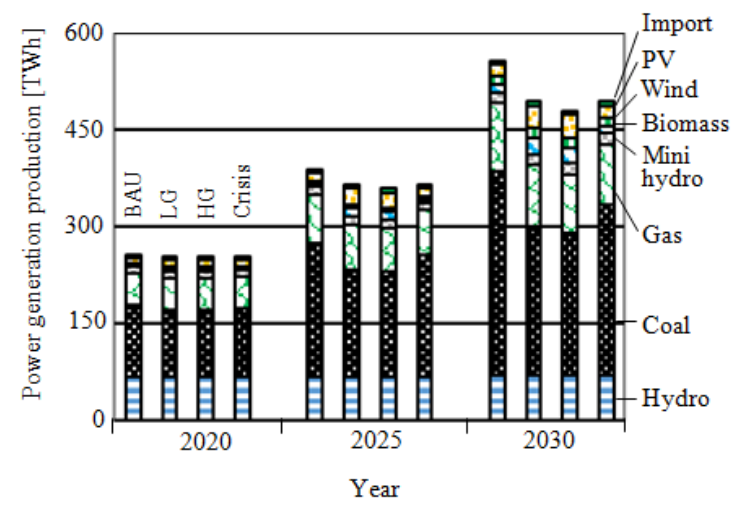

Fig. 2. Optimum power generation production

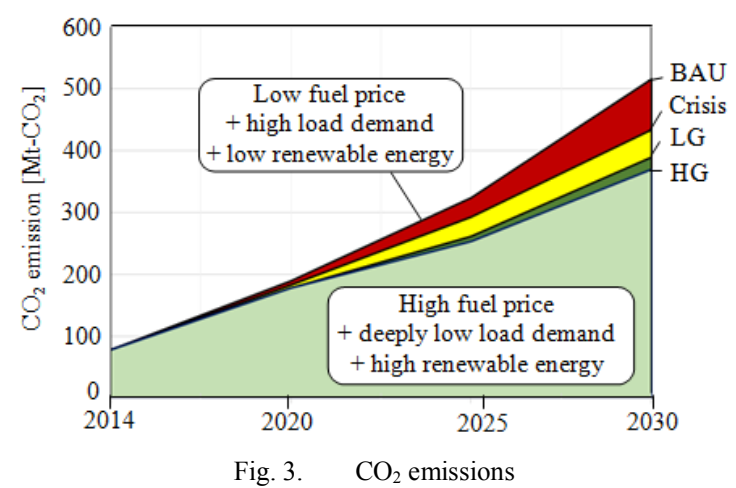

TABLE XVIII. $\mathrm{CO}_{2}$ REDUCTION COMPARED TO BAU

\begin{tabular}{|c|c|c|c|}
\hline Scenario & $\mathbf{2 0 2 0}$ & $\mathbf{2 0 2 5}$ & $\mathbf{2 0 3 0}$ \\
\hline LG & 11.14 & 62.04 & 127.74 \\
\hline HG & 11.14 & 69.60 & 146.92 \\
\hline Crisis & 6.05 & 30.80 & 2.38 \\
\hline
\end{tabular}

\section{Generation Cost}

Generation costs for both two cases of non-selling $\mathrm{CO}_{2}$ emissions and selling mitigated $\mathrm{CO}_{2}$ are shown in Figure 4. Two ranges of generation cost, 4.3-5.5 and 6.0-7.7 US\$cent $/ \mathrm{kWh}$ have been reached in correspondence with low and high fuel price future scenarios. It is demonstrated that selling mitigated $\mathrm{CO}_{2}$ will help reduce the generation cost. Maximum reduced cost is recorded in $\mathrm{HG}$ scenario in 2030 at $10 \%$ in case of non-selling mitigated $\mathrm{CO}_{2}$. Maximum amount of selling $\mathrm{CO}_{2}$ emission reduction is 2.64 billion US\$ in $\mathrm{HG}$ scenario in 2030. This helps generation cost of both $\mathrm{HG}$ and Crisis scenarios to be nearly the same in 2030. Selling mitigated $\mathrm{CO}_{2}$ also makes generation cost of LG scenario in 2030 lower than that of BAU. BAU scenario has the same cost for both cases of selling and non-selling mitigated $\mathrm{CO}_{2}$ as it has no emission reduction.

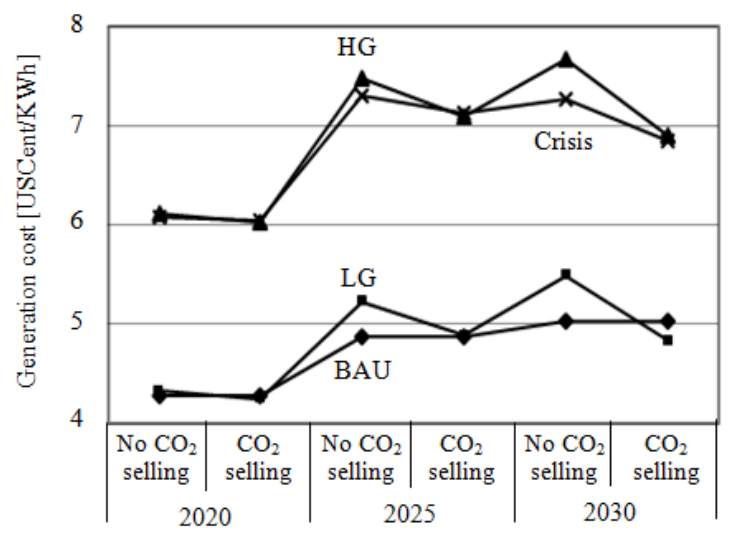

Fig. 4. Electricity generation cost

\section{CONCLUSION}

Four projection scenarios of power generation by 2030 in Vietnam have been proposed. Three variable key-factors have been selected for creating the power generation scenarios: future fuel price, reduction of load demand caused by the penetration of LED technology and rooftop PV systems, and the introduction of power generation from renewable sources. The scenarios named BAU, LG, HG, and Crisis are taken into account for finding the optimum structure of power generation system in terms of installed capacity and power generation production. $\mathrm{CO}_{2}$ emission reduction compared to $\mathrm{BAU}$ scenario and its effects on reducing generation cost are calculated with the aim to give an understanding of the magnitude of the impact of green scenarios on the power generation system.

BAU is the worst scenario in terms of $\mathrm{CO}_{2}$ emissions because of the highest proportion of generation from coal and fossil fuels. It also leads to a poor energy security because thermal generations increase their generation share at about $62.6 \%, 72.5 \%$, and $75.1 \%$ of total in 2020,2025 , and 2030 , respectively. LG and HG scenarios show their positive impacts on $\mathrm{CO}_{2}$ emissions and generation cost reduction. $\mathrm{HG}$ scenario is defined as the greenest one when renewable energy sources contribute $11.2 \%$ (2020), 15.5\% (2025), and 19.4\% (2030) of total generation. Maximum emission reduction is about 146.92Mt- $\mathrm{CO}_{2}$ in $\mathrm{HG}$ scenario in 2030. Additionally, selling mitigated $\mathrm{CO}_{2}$ can make green scenarios more competitive to BAU and Crisis in terms of cost. Two ranges of generation cost (4.3-5.5 and 6.0-7.7US\$cent/kWh) have been reached in correspondence with the low and high fuel price scenarios. These generation costs are low enough to support future sustainable economic development in Vietnam. Replacing conventional electric lamps with LED lamps and increasing the installed capacity of rooftop PVs may help reducing electric load demand. Increasing the contribution of renewable generation will make the HG scenario become more attractive both in environmental and economic aspects when the Crisis scenario comes. Generation costs of all scenarios shall become 
cheap enough for promoting economic development in Vietnam to 2030.

\section{REFERENCES}

[1] IEA, World Energy Outlook 2017, IEA, 2017

[2] BP, BP Energy Outlook 2035, BP, 2015

[3] G. Fan, N. Stern, O. Edenhofer, S. Xu, K. Eklund, F. Ackerman, L. Li, K. Halding, The Economics of Climate Change in China: Towards a Low-Carbon Economy, Stockholm Environment Institute, 2011

[4] M. R. Salehizadeh, "A. Rahimi-Kian, K. Hausken, A Leader-Follower Game on Congestion Management in Power Systems", in: Game Theoretic Analysis of Congestion, Safety and Security, pp. 81-112, Springer, 2015

[5] M. R. Salehizadeh, S. Soltaniyan, "Application of Fuzzy Q-Learning for Electricity Market Modeling by Considering Renewable Power Penetration", Renewable and Sustainable Energy Reviews, Vol. 56, pp. 1172-1181, 2016

[6] M. R. Salehizadeh, A. Rahimi-Kian, M. Oloomi-Buygi, “A Multi-Attribute Congestion-Driven Approach for Evaluation of Power Generation Plants", International Transactions on Electrical Energy Systems, Vol. 25, No. 3, pp. 482-497, 2015

[7] M. R. Salehizadeh, A. Rahimi-Kian, M. Oloomi-Buygi, "Security-Based Multi-Objective Congestion Management for Emission Reduction in Power System", International Journal of Electrical Power \& Energy Systems, Vol. 65, pp. 124-135, 2015

[8] W. Wangiiraniran, B. Eua-Arporn, "Assessment of Renewable Energy Penetration on Power Development Plan in Thailand", Journal of Power and Energy Systems, Vol. 5, No. 3, pp. 209-217, 2011

[9] N. T. Dung, Decision 428/QD-TTg, March, 18, 2016 of the Prime Minister of Vietnam, Revisions to the National Power Development Plan from 2011 to 2020 with Visions Extended to 2030, 2016

[10] H. T. Nguyen, "Main Drivers of Carbon Dioxide Emissions in Vietnam Trajectory 2000-2011: An Input-Output Structural Decomposition Analysis", Journal of Sustainable Development, Vol. 11, No. 4, pp. 129147,2018

[11] N. X. Phuc, Decision 11/QD-TTg, April, 14, 2017 of the Prime Minister of Vietnam, Support Mechanisms for the Development of Solar Power Projects in Vietnam, 2017

[12] Department of Energy \& Climate Change - UK, DECC Fossil Fuel Price Projections, 2013

[13] V. H. M. Nguyen, C. V. Vo, K. T. P. Nguyen, B. T. T. Phan, "Forecast on 2030 Vietnam Electricity Consumption", Engineering, Technology \& Applied Science Research, Vol. 8, No. 3, pp. 2869-2874, 2018

[14] V. H. M. Nguyen, C. V. Vo, B. T. T. Phan, "Peak Load Forecasting for Vietnam National Power System to 2030", Journal of Science \& Technology of Technical Universities - Hanoi University of Science and Technology, No. 123, pp. 7-13, 2017

[15] N. T. Dung, Decision 2068/QD-TTg, November, 25, 2015 of the Prime Minister of Vietnam, The Development Strategy of Renewable Energy of Vietnam by 2030 with a Vision to 2050, 2015

[16] V. H. M. Nguyen, A. N. Nguyen, C. V. Vo, B. T. T. Phan, "Forecasting Vietnam's Electric Load Profile to 2030", Journal of Technical Education Science, Vol. 49, pp. 51-57, 2018

[17] J. Polo, S. Martinez, C. M. Fernandez-Peruchena, A. Navarro, J. M. Vindel, M. Gaston, L. R. Santigosa, E. Soria, M. V. Guisado, A. Bernados, I. Pagola, M. Olano, Maps of Solar Resource and Potential in Viet Nam, Ministry of Industry and Trade of the Socialist Republic of Vietnam, 2015

[18] AWS Truepower, Wind Resource Atlas of Vietnam, 2011

[19] V. V. Cuong, "CO2 life cycle emission factors of power generation in Vietnam", Journal of Science \& Technology of Technical Universities Hanoi University of Science and Technology, Vol. 79, 102-107, 2010

[20] NREL, Life Cycle Greenhouse Gas Emissions from Solar Photovoltaics, NREL/FS-6A20-56487, NREL, 2012

[21] R. C. Thomson, G. P. Harrison, Life Cycle Costs and Carbon Emissions of Wind Power, University of Edinburgh, 2015
[22] Synapse Energy Economics, Carbon Dioxide Price Forecast, Synapse Energy Economics Inc., 2015

[23] Ministry of Industry and Trade, Decision 942/QD-BCT, March, 11, 2016 of the Minister of Ministry of Industry \& Trade, Vietnam, Avoiding Cost Appling for Bimass Power Projects in 2016, 2016

[24] N. X. Phuc, Decision 39/2018/QD-TTg, September, 10, 2018 of the Prime Minister of Vietnam, Amending Several Articles of Decision No. 37/2011/qd-ttg Dated June 29, 2011 of The Prime Minister on Provison of Assistance in Development of Wind Power Projects in Vietnam, 2018 